\title{
A New Evapotranspiration Model Accounting for Advection and Its Validation during SMEX02
}

\author{
Yongmin Yang, ${ }^{1,2}$ Hongbo Su, ${ }^{1}$ Renhua Zhang, ${ }^{1}$ Jianjun $W u,{ }^{3}$ and Jianwei Qi ${ }^{4}$ \\ ${ }^{1}$ Key Laboratory of Water Cycle \& Related Land Surface Processes, Institute of Geographic Sciences and Natural Resources Research, \\ Beijing 100101, China \\ ${ }^{2}$ Graduate University of Chinese Academy of Sciences, Beijing 100049, China \\ ${ }^{3}$ Academy of Disaster Reduction and Emergency Management, Beijing Normal University, Beijing 100875, China \\ ${ }^{4}$ China Aero Geophysical Survey \& Remote Sensing Center for Land and Resources, Beijing 100083, China
}

Correspondence should be addressed to Hongbo Su; hongbo@ieee.org

Received 19 June 2013; Accepted 16 October 2013

Academic Editor: Xiangzheng Deng

Copyright (c) 2013 Yongmin Yang et al. This is an open access article distributed under the Creative Commons Attribution License, which permits unrestricted use, distribution, and reproduction in any medium, provided the original work is properly cited.

Based on the crop water stress index (CWSI) concept, a new model was proposed to account for advection to estimate evapotranspiration. Both local scale evaluation with sites observations and regional scale evaluation with a remote dataset from Landsat 7 ETM+ were carried out to assess the performance of this model. Local scale evaluation indicates that this newly developed model can effectively characterize the daily variations of evapotranspiration and the predicted results show good agreement with the site observations. For all the 6 corn sites, the coefficient of determination $\left(R^{2}\right)$ is 0.90 and the root mean square difference (RMSD) is $58.52 \mathrm{~W} / \mathrm{m}^{2}$. For all the 6 soybean sites, the $R^{2}$ and RMSD are 0.85 and $49.46 \mathrm{~W} / \mathrm{m}^{2}$, respectively. Regional scale evaluation shows that the model can capture the spatial variations of evapotranspiration at the Landsat-based scale. Clear spatial patterns were observed at the Landsat-based scale and are closely related to the dominant land covers, corn and soybean. Furthermore, the surface resistance derived from instantaneous CWSI was applied to the Penman-Monteith equation to estimate daily evapotranspiration. Overall, results indicate that this newly developed model is capable of estimating reliable surface heat fluxes using remotely sensed data.

\section{Introduction}

Evapotranspiration $(E T)$ is a very important process which relates to energy and water exchange between the hydrosphere, atmosphere, and biosphere $[1,2]$. The research on evapotranspiration is very crucial to further our understanding of global climate change, land-atmosphere interaction, water cycle, and ecological studies [3-5]. Recently, the "evaporation paradox," which is referred to as the decreasing pan observations and the increasing surface air temperature over the past 50 years, has been reported in many regions around the world [6-8]. Pan evaporation provides a measurement of the integrated effect of radiation, wind, temperature, and humidity on the evaporation from an open water surface. Actual evaporation is the quantity of water that is actually removed from natural surfaces. There is a need to understand the change of actual evapotranspiration at regional and global scales behind evaporation paradox. Actual evapotranspiration is a key factor to understand the regional water cycle and energy balance. An in-depth understanding of regional evapotranspiration will benefit the water resource planning and management in arid and semiarid areas [9].

As a promising means of land surface observation, remote sensing has some salient characteristics, such as large scale coverage, multitemporal observation, and low cost, and it provides excellent datasets for estimating regional evapotranspiration [10]. Many studies have been carried out on the retrieval of regional evapotranspiration based on remote sensing. A lot of remote sensing based evapotranspiration models have been proposed and used in different regions of the world. Jackson et al. [11, 12] is one of the pioneers who investigated the regional evaporation retrieval based on thermal infrared observations from remote sensing. Subsequently, many scholars developed different kinds of 
models based on different assumptions. These models can be roughly divided into four categories. (1) The first category is empirical/statistical models $[13,14]$. As a good example of this category, Jung et al. [15] estimate global land-ET based on FLUXNET, remote sensing, and meteorological observations. (2) The second one is surface energy balance based single and dual source models [16-20]. The surface energy balance system (SEBS) model developed by $\mathrm{Su}[20]$ is a good example of the surface energy balance-based single source model. The two-source approach proposed by Norman et al. [19] to distinguish vegetation transpiration and soil evaporation is a good representation of the surface energy balance-based two source model. Coupled with a time-integrated component connecting surface sensible heating with planetary boundary layer development, Anderson et al. [21] proposed a twosource time-integratedmodel for estimating surface fluxes. Recently, the Atmosphere-Land Exchange Inverse (ALEXI) model was developed by Anderson et al. [16, 17] and they applied this model to study the continental evapotranspiration based on thermal infrared observations from geostationary satellites. (3) The third category is spatial contextual models based on land surface temperature-vegetation index space (Ts/VI). This category includes the works by Moran et al. [22], Roerink et al. [23], Jiang and Islam [24], Zhang et al. [25, 26], Wang et al. [27], Stisen et al. [28], and Shu et al. [29]. In general, three types of feature space are often used in the spatial contextual models. They are LST/NDVI space, LST/albedo space, and $\Delta T / \mathrm{NDVI}(\Delta T$, temporal changes of LST). Comprehensive reviews of models in this category can be found in the recent papers by Carlson [30] and Petropoulos et al. [31]. (4) The fourth one is Penman-Monteith equation based models. Cleugh et al. [32] used NDVI and LAI to calculate surface resistance and applied this approach to map the regional ET for Australia from 2001 to 2004. Later, Mu et al. $[33,34]$ further revised Cleugh's approach and developed a global remote sensing ET algorithm. Comprehensive reviews of methodologies for regional ET estimation from remotely sensed data can be found in the papers by Kalma et al. [35] and Li et al.[36].

Although great progress has been made on ET estimation based on remote sensing, there are still many pending issues that have not been solved properly. Firstly, advection having great impact on ET has been reported by many field measurements [37]. Wang et al. [38] noticed a significant "desert-oasis effect" in the Heihe River Basin Field Experiment (HEIFE). Tolk et al. [39, 40] observed that ET can be enhanced greatly by advection in the semiarid regions of the southern High Plains. In some experiments, ET can even exceed net incoming radiation due to advection from the surrounding landscape. Allen et al. [41] found that $24 \mathrm{~h} \mathrm{ET} \mathrm{from} \mathrm{alfalfa,} \mathrm{as}$ measured by lysimeters, is larger than net radiation (Figure 1 in his paper). Oke [42] also observed that daily ET from a minilysimeter exceeds the net radiation. Rijks [43] found that the evaporation rate is 1.8 times greater than the supply of net radiation. It is not uncommon in semiarid, advective environments to have ET that exceeds $\left(R_{n}-G\right)$ by $30-50 \%$ (Terry A. Howell, 2011, personal communication). However, $\left(R_{n}-G\right)$ is often used as the potential rate of ET in most surface energy balance-based single and dual source models.
Penman-Monteith equation based models may be useful under advective environments, but the parameterization scheme of the surface resistance based on LAI and NDVI is far from being validated. Secondly, the development of an accurate method for extrapolating instantaneous estimates to daily values is imperative. The evaporative fraction method is widely used to derive daily ET [20]. However, contrary conclusions have been drawn by different scholars. Chávez et al. [44] evaluated six extrapolation methods and they suggested that the evaporative fraction method showed the best performance. Farah et al. [45] evaluated the temporal variability of the evaporative fraction in a tropical watershed and found a good relationship between daily and average day evaporative fraction. While Crago [46] derived a quite different conclusion, he suggests that a complicated combination of weather conditions, soil moisture, and biophysical conditions contributes to the conservation of evaporative fraction. Hoedjes et al. [47] showed that evaporative fraction is almost constant under dry conditions, but it is depicted as a concave shape under wet conditions. The reference ET based extrapolation fraction method was proposed by Allen et al. [48] to scale daily ET from instantaneous ET values. However, Chávez et al. [44] indicated that this method overestimates daily ET by about $4 \pm 10.0 \%$ (MBE \pm RMSE).

In this paper, a new ET model was proposed to account for advection based on the crop water stress index (CWSI), and then this method was employed to estimate ET at both local and regional scales. Section 2 presents a description of ET from natural nonsaturated surfaces and the CWSI concept. Section 3 introduces the datasets used to assess the model at site scale and regional scale. Section 4 firstly reports the evaluation of the model performance at site scales and then presents the results of the model applied to regional scale with variables from Landsat based variables. In the remainder of Section 4, daily ET was estimated using the surface resistance derived from CWSI. Section 5 discusses the limitations in this work and the final section gives a conclusion.

\section{Theory and Methodology}

2.1. Evaporation from Natural Nonsaturated Surfaces. Monteith [49] developed the Penman equation and extended it to cropped surfaces by introducing surface and aerodynamic resistance. The Penman-Monteith form of the evaporation can be written as follows:

$$
\begin{gathered}
E=\frac{\Delta\left(R_{n}-G\right)+\gamma E a}{\Delta+\gamma\left(1+\left(r_{s} / r_{a}\right)\right)}, \\
E a=\frac{\rho_{a} C_{p}\left(e_{a}^{s}-e_{a}\right)}{\gamma r_{a}},
\end{gathered}
$$

where $E a$ is the air drying power, $\rho_{a}$ is the air density, $e_{a}^{s}$ is the saturation vapor pressure of the air, $e_{a}$ is the actual vapor pressure of the air, $C_{p}$ is the specific heat of air at a constant pressure, and $r_{s}$ and $r_{a}$ are the (bulk) surface and aerodynamic resistance. This formula is also valid for soil surface with 
properly defined surface and aerodynamic resistance. This formula can be simplified as follows:

$$
\begin{gathered}
E=\frac{\Delta}{\Delta+\gamma / S}\left(R_{n}-G\right)+\frac{\gamma}{\Delta+\gamma / S} E_{a}, \\
S=\frac{r_{a}}{r_{a}+r_{s}} .
\end{gathered}
$$

For a wet surface, $S$ equals unit one and this formula is just the same as the Penman equation; for a very dry surface, $S$ approaches zero; then $\gamma / S$ is undefined because of division by zero, and the evaporation rate nearly equals zero. Equation (2) is similar to the general expression for evaporation derived by Granger and Gray [50]. However, Granger and Gray termed $S$ as relative evaporation, and they gave an exponential function to determine the relative evaporation. Assuming that $r_{s}$ equals zero (or $S$ equals unit one) and the surface is wet, (2) and (3) are useful to derive potential $E T(E p)$ for nonsaturated surfaces. Potential ET is defined as the amount of evaporation that would occur if a sufficient water source was available. In other words, potential ET is referred to the available energy that could be used for ET. Advection is accounted for in the formula through air drying power [51]. If the potential ET equals the local available energy $\left(R_{n}-G\right)$, this is called the heat balance status and the sum of sensible $(H)$ and the latent heat flux $(L E)$ will equal $\left(R_{n}-G\right)$. However, due to the stability of the atmosphere, the air drying power is changing due to the variations of meteorological variables. Under such conditions the potential ET will not be equal to the local available energy $\left(R_{n}-G\right)$. Therefore, the advection part can be defined as

$$
\Delta Q=E p-\left(R_{n}-G\right) .
$$

Therefore, the ratio of ET and potential ET ( $r_{s}$ equals zero or $S$ equals unit one) can be derived as follows:

$$
\frac{E}{E_{p}}=\frac{\Delta+\gamma}{\Delta+\gamma\left(1+r_{s} / r_{a}\right)}=\frac{\Delta+\gamma}{\Delta+\gamma / S} .
$$

2.2. Crop Water Stress Index and Surface Resistance. Jackson et al. $[52,53]$ exploited the relationship between the plantair temperature difference and the vapor pressure deficit to develop the crop water stress index (CWSI). In this part, a simple modification is applied to the derivation of CWSI in order to clearly demonstrate the advection effects. The development of the CWSI is based on the energy balance equation as well as the profile equations for sensible heat flux $(H)$ and latent heat flux $(\lambda E)$ :

$$
\begin{gathered}
R_{n}-G=H+L E, \\
H=\frac{\rho_{a} C_{p}\left(T_{c}-T_{a}\right)}{r_{a}}, \\
L E=\frac{\rho_{a} C_{p}\left(e_{c}^{*}-e_{a}\right)}{\left(\gamma\left(r_{a}+r_{c}\right)\right)},
\end{gathered}
$$

where $T_{c}$ is the surface temperature, $T_{a}$ is the air temperature, and $e_{c}^{*}$ is the saturated vapor pressure of the air at $T_{c}$.
For the dry limit, $L E$ will nearly equal zero and the maximum difference between $T_{c}$ and $T_{a}$ can be derived as follows:

$$
\begin{gathered}
H_{\text {dry }}=\frac{\rho_{a} C_{p}\left(T_{c}-T_{a}\right)}{r_{a}}=R_{n}-G, \\
\left(T_{c}-T_{a}\right)_{\max }=\frac{r_{a}\left(R_{n}-G\right)}{\rho_{a} C_{p}} .
\end{gathered}
$$

For the wet limit, the evaporation rate will equal potential ET and the difference between $T_{c}$ and $T_{a}$ can be derived as follows:

$$
\begin{gathered}
H_{\mathrm{wet}}=\frac{\rho_{a} C_{p}\left(T_{c}-T_{a}\right)}{r_{a}}=\left(R_{n}-G\right)-E p, \\
\left(T_{c}-T_{a}\right)_{\min }=\frac{r_{a}\left(\left(R_{n}-G\right)-E p\right)}{\rho_{a} C_{p}}=\frac{r_{a}(-\Delta Q)}{\rho_{a} C_{p}} .
\end{gathered}
$$

Equation (9) is very helpful to understand some experiment results of the advection effect on ET. Surface temperature can be lower than air temperature when $\Delta Q$ is greater than zero, and this is a more general explanation for the work of Ehrler [54], who found that the leaf temperature could be cooler than the air temperature. Also this is in accordance with observation results of Regional Advection Perturbations in an Irrigation Desert experiment (RAPID). De Bruin et al. [55] found negative $H$ both during day and night times; $\lambda E$ is greater than $R_{n}$ and at night it is greater than 0 . CWSI is further defined by Jackson et al. $[52,53]$ as

$$
\text { CWSI }=\frac{\left(T_{c}-T_{a}\right)-\left(T_{c}-T_{a}\right)_{\min }}{\left(T_{c}-T_{a}\right)_{\max }-\left(T_{c}-T_{a}\right)_{\min }},
$$

where $\left(T_{c}-T_{a}\right)$ is the measured temperature difference. Menenti and Choudhury [56] redefined the parameterization of CWSI and name the parameterization as the Surface Energy Balance Index (SEBI). They further proposed to use air potential temperature at the top of the atmospheric boundary layer instead of near surface air temperature. In fact, the air temperature and humidity of the near surface layer have more direct impacts on $\operatorname{ET}[57,58]$. In this study, we still use the original parameterization of Jackson et al. Therefore, combining with (5), the following relationship can be derived:

$$
1-\mathrm{CWSI}=\frac{E}{E_{p}}=\frac{\Delta+\gamma}{\Delta+\gamma\left(1+r_{s} / r_{a}\right)}=\frac{\Delta+\gamma}{\Delta+\gamma / S} .
$$

The equation clearly demonstrates the relationship between $r_{s}$ and CWSI. Therefore, with properly defined $r_{a}, r_{s}$ and $S$ can be derived from CWSI. When $E_{p}$ equals $\left(R_{n}-G\right)$, the above equation will be the same as the evaporative fraction defined by $\mathrm{Su}[20]$. There are two attractive features of this equation. Firstly, advection effects are accounted for in the parameterization of CWSI and this may be applicable to advective environment. Secondly, $r_{s}$ can be derived from CWSI with few assumptions, and this would be an operational method for extrapolating instantaneous estimates to daily values. 
2.3. Aerodynamic Resistance. Aerodynamic resistance is a very important parameter for estimating sensible and latent heat flux with remotely sensed data. Many parameterizations of aerodynamic resistance have been proposed by different researchers based on different assumptions and different observations. [59-61]. Liu et al. [62] evaluated eight parameterizations for aerodynamic resistance using the measurements of sensible heat flux, air temperature, and surface temperature. Liu's work provides a good reference for parameterization of $r_{a}$. Liu et al. [62] pointed out that the roughness length for heat and vapor transfer is a crucial parameter and cannot be taken as a constant or be neglected. In this study, the aerodynamic resistance was determined on the basis of the Monin-Obukhov surface layer similarity theory [63]:

$$
\begin{aligned}
r_{a}= & \left(\left[\ln \left[\frac{\left(z_{m}-d\right)}{z_{\text {om }}}\right]-\psi_{m}\left(\frac{\left(z_{m}-d\right)}{L}\right)\right]\right. \\
& \left.\times\left[\ln \left[\frac{\left(z_{m}-d\right)}{z_{o h}}\right]-\psi_{h}\left(\frac{\left(z_{m}-d\right)}{L}\right)\right]\right) \\
& \times\left(k^{2} u_{z}\right)^{-1},
\end{aligned}
$$

where $z_{m}$ is the height of wind measurements, $z_{h}$ is the height of humidity measurements, $d$ is the zero plane displacement height, $z_{\text {om }}$ is the roughness length governing momentum transfer, $z_{o h}$ is the roughness length governing transfer of heat and vapour, $k$ is the von Karman's constant, $u_{z}$ is the wind speed at height $z_{m}$, and $L$ is the Obukhov length. $\psi_{m}$ and $\psi_{h}$ are the integral forms of the stability correction functions for heat transfer and momentum exchange, respectively. In unstable and neutral stability conditions, the stability correction functions were determined by Paulson [64]:

$$
\begin{gathered}
\psi_{m}=2 \ln \left[\frac{(1+x)}{2}\right]+\ln \left[\frac{\left(1+x^{2}\right)}{2}\right]-2 \arctan (x)+\frac{\pi}{2}, \\
\psi_{h}=2 \ln \left[\frac{\left(1+x^{2}\right)}{2}\right] .
\end{gathered}
$$

In stable conditions, the stability correction can be expressed as $[65,66]$

$$
\psi_{m}=\psi_{h}=-5 \xi
$$

where $x=(1-16 \xi)^{0.25}$ and $\xi=\left(z_{m}-d\right) / L$. More details of this parameterization can be found in the papers by Katul and Parlange [67] and Liu et al. [68]. The roughness length of momentum transfer and zero plane displacement can be parameterized as [69]

$$
\begin{gathered}
z_{\text {om }}=0.13 h, \\
d=0.63 h,
\end{gathered}
$$

where $h$ is the crop height. The roughness length for heat transfer is parameterized by Kustas et al. [70] as

$$
\ln \left(\frac{z_{\text {om }}}{z_{\text {oh }}}\right)=0.17 u_{z}\left(T_{c}-T_{a}\right) .
$$

\section{Study Area and Data Description}

3.1. SMACEX02 Experiment. The Soil Moisture-Atmosphere Coupling Experiment (SMACEX) was designed to provide a multiscale dataset of vegetation, soil, and atmospheric states $[71,72]$. It was undertaken over Iowa, US, from June 19 through July 9 in 2002. The primary objective was to extend microwave soil moisture observations and retrieval algorithms to changing crop biomass conditions and to provide validation data for the Advanced Microwave Scanning Radiometer (AMSR) brightness temperature and soil moisture retrieval algorithms. The Walnut Creek watershed was the core study area of this experiment. The land cover in the Walnut Creek watershed is primarily comprised of corn and soybean. The details of this experiment can be found in the paper by Kustas et al. [71].

3.2. Tower Measurements. Most of the SMACEX measurements include the surface energy, water, and carbon fluxes, as well as mean and turbulent atmospheric boundary properties. Twelve field sites with eddy covariance (EC) were deployed in the central area of the study. There were 6 corn sites and 6 soybean sites. However, for the WC03 site, the land cover was classified as soybean in the field notes but was located in a corn field based on the provided coordinates [73]. The towers were instrumented with sensors to measure turbulent fluxes of water vapor and sensible heat, as well as net radiation and soil heat flux at $30 \mathrm{~min}$ intervals. The distribution of flux towers in the Walnut Creek catchment and the land use classifications are provided in Figure 1. Additional hydrometeorological observations included wind speed and direction, air temperature, vapor pressure, nearsurface soil temperature, and moisture at $10 \mathrm{~min}$ intervals. In this study, the hydrometeorological data were resampled to $30 \mathrm{~min}$ to be compatible with heat flux measurements. Correction was performed using the approach suggested by Twine et al. [74], which assumes that the energy nonclosure is caused by EC underestimation, while the corresponding Bowen ratio is correctly estimated. Based on this approach, sensible and latent heat fluxes were adjusted by forcing the energy balance closure using the measured net solar radiation, soil heat flux, and Bowen ratio. The tower based composite radiometric surface temperature was measured by Apogee infrared thermometers. Su et al. [72] corrected the tower-based composite radiometric surface temperature and applied it to evaluate the SEBS model. In this study, the correction method proposed by $\mathrm{Su}$ was employed. In our revised model, vegetation height is a very important parameter. During the experiment, LAI, vegetation fraction, and vegetation height were measured at each site on 18 and 28 June and 2 and 5 July. In this study, the vegetation height was set as $1.5 \mathrm{~m}$ for the corn sites and $0.35 \mathrm{~m}$ for the soybean sites.

3.3. Remote Sensing Dataset. In this study, one scene from the Enhanced Thematic Mapper plus (ETM+) on Landsat 7 acquired at 10:40 local time on DOY 182 of 2002 was used. The remote sensing dataset is obtained from the National Snow and Ice Data Center (http://nsidc.org/index.html). Emissivity 
TABLE 1: Meteorological data and remote sensing data used in this study.

\begin{tabular}{|c|c|c|}
\hline & $\begin{array}{c}\text { Instantaneous estimation } \\
\text { (satellite overpass time value) }\end{array}$ & $\begin{array}{l}\text { Daily ET estimation } \\
\text { (daily mean value) }\end{array}$ \\
\hline \multicolumn{3}{|l|}{ Meteorological variables } \\
\hline Incoming solar radiation $\left(\mathrm{W} / \mathrm{m}^{2}\right)$ & 958 & 344.72 \\
\hline Air temperature $\left({ }^{\circ} \mathrm{C}\right)$ & 29.35 & 27.31 \\
\hline Water vapour pressure $(\mathrm{kPa})$ & 2.2 & 2.22 \\
\hline Wind speed $(\mathrm{m} / \mathrm{s})$ & 5.32 & 5.16 \\
\hline Atmospheric pressure $(\mathrm{kPa})$ & 98.2 & 98.5 \\
\hline Remote sensing data & \multicolumn{2}{|c|}{ Landsat ETM+ } \\
\hline Overpass time (Local time) & $11: 40$ & $11: 40$ \\
\hline Model resolution & $60 \mathrm{~m}$ & $60 \mathrm{~m}$ \\
\hline LST resolution & $60 \mathrm{~m}$ & $60 \mathrm{~m}$ \\
\hline Albedo & $60 \mathrm{~m}$ & $60 \mathrm{~m}$ \\
\hline Emissivity & $60 \mathrm{~m}$ & $60 \mathrm{~m}$ \\
\hline Classification & \multicolumn{2}{|c|}{ Aggregated from Landsat based classification } \\
\hline
\end{tabular}

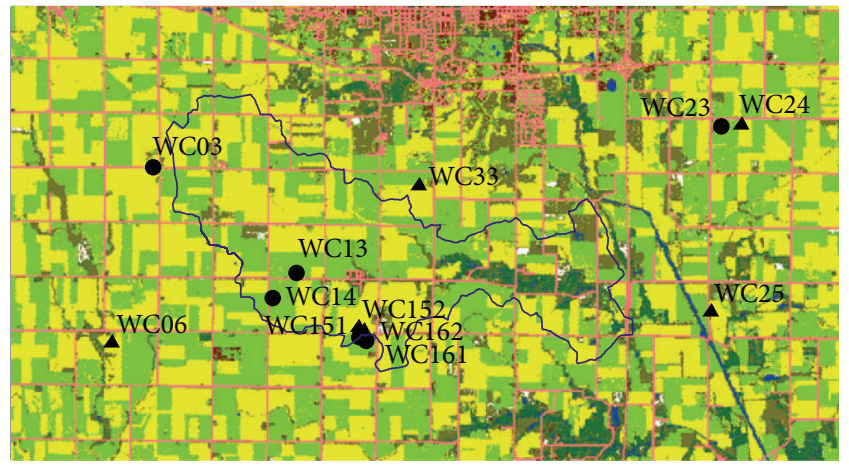

\begin{tabular}{ll}
\hline Soybean site & $\square$ Urban \\
Corn site & Trees \\
\hline Watershed & $\square$ Soybean \\
Roads & Grass \\
Water & $\square$ Corn
\end{tabular}

FIgURE 1: The distribution of flux towers in the Walnut Creek catchment and the land use classifications.

was derived with the fractional cover mixing model proposed by Sobrino et al. [75]. The land surface temperature was derived from the thermal band of the Landsat imagery based on the method proposed by Li et al. [76]. Albedo was derived from the visible and near-infrared bands of the Landsat imagery using algorithm in Liang [77] and Liang et al. [78]. Land cover classification for the SMEX02 area was obtained from Landsat ETM dataset, which is available from the National Snow and Ice Data Center. The vegetation height was parameterized using the land cover classification. The details of the meteorological data and remote sensing data used in this study are listed in Table 1.

In this study, the net radiation is estimated from the radiative energy balance which is expressed as

$$
R_{n}=(1-\alpha) R_{\mathrm{swd}}+\varepsilon R_{\mathrm{lwd}}-\epsilon \sigma T_{s}^{4},
$$

where $\alpha$ is the broadband albedo, $\varepsilon$ is the emissivity in the thermal infrared band, $R_{\text {swd }}$ is the incident solar radiation, $R_{\mathrm{Iwd}}$ is the downward longwave radiation, and $\sigma$ is the Stephan-Boltzmann constant. The soil heat flux is also an important component in the energy balance equation. Following Choudhury et al. [79], the soil heat flux is parameterized as

$$
G_{0}=R_{n}\left(\tau_{v} f+\tau_{s}(1-f)\right),
$$

where $\tau_{v}$ and $\tau_{s}$ are the soil heat flux ratios for the vegetation area and bare soil areas and $f$ is the vegetation fraction. The fractional vegetation cover was estimated from the normalized difference vegetation index (NDVI) [80]:

$$
f=\frac{\mathrm{NDVI}-\mathrm{NDVI}_{\min }}{\mathrm{NDVI}_{\max }-\mathrm{NDVI}_{\min }},
$$

where $\mathrm{NDVI}_{\max }$ and $\mathrm{NDVI}_{\min }$ are NDVI values for vegetation cover and bare soil, respectively.

\section{Results}

4.1. Sites Evaluation. The ET model was applied to the site scale of SMACEX02 with a $30 \mathrm{~min}$ time step. Predicted ET from the proposed model was compared with the observation from the eddy covariance system. Two strategies were used to assess the performance of this new model. Firstly, time variations of modeled latent heat flux and the corrected eddy covariance measurements are compared through DOY 171190. Figures 2 and 3 represent the modeled results compared with the observations for WC 06 (corn site) and WC03 (soybean site), respectively. The results indicate that the modeled ET is in good agreement with the observations except for a slight underestimation at night time at both sites. The mean absolute difference (MAD) and the root mean square difference (RMSD) are $41.90 \mathrm{~W} / \mathrm{m}^{2}$ and $50.63 \mathrm{~W} / \mathrm{m}^{2}$ for the WC06 site. The MAD and RMSD are $30.75 \mathrm{~W} / \mathrm{m}^{2}$ and $38.22 \mathrm{~W} / \mathrm{m}^{2}$ for the WC03 site. Quantitative measures of the 
TABLE 2: Quantitative measures of model performance.

\begin{tabular}{|c|c|c|c|c|c|}
\hline Site & $N$ & $\operatorname{MAD}\left(\mathrm{W} / \mathrm{m}^{2}\right)$ & $\operatorname{RMSD}\left(\mathrm{W} / \mathrm{m}^{2}\right)$ & $R^{2}$ & $\operatorname{Bias}\left(\mathrm{W} / \mathrm{m}^{2}\right)$ \\
\hline WC03 & 835 & 30.75 & 38.22 & 0.93 & -20.27 \\
\hline WC06 & 840 & 41.9 & 50.63 & 0.92 & -26.26 \\
\hline WC13 & 771 & 48.1 & 62.2 & 0.66 & 0.92 \\
\hline WC14 & 827 & 32.91 & 55.09 & 0.87 & 5.36 \\
\hline WC23 & 625 & 19.99 & 27.3 & 0.96 & 10.79 \\
\hline WC24 & 538 & 52.17 & 76.26 & 0.86 & -14.87 \\
\hline WC25 & 488 & 50.38 & 67.86 & 0.8 & 3.51 \\
\hline WC33 & 801 & 38.27 & 48.25 & 0.92 & -21.51 \\
\hline WC151 & 372 & 38.05 & 49.39 & 0.93 & -17.74 \\
\hline WC152 & 789 & 47.81 & 59.67 & 0.89 & 18.725 \\
\hline WC161 & 664 & 42.2 & 57.96 & 0.83 & 13.19 \\
\hline WC162 & 772 & 37.33 & 45.32 & 0.91 & -27.04 \\
\hline
\end{tabular}

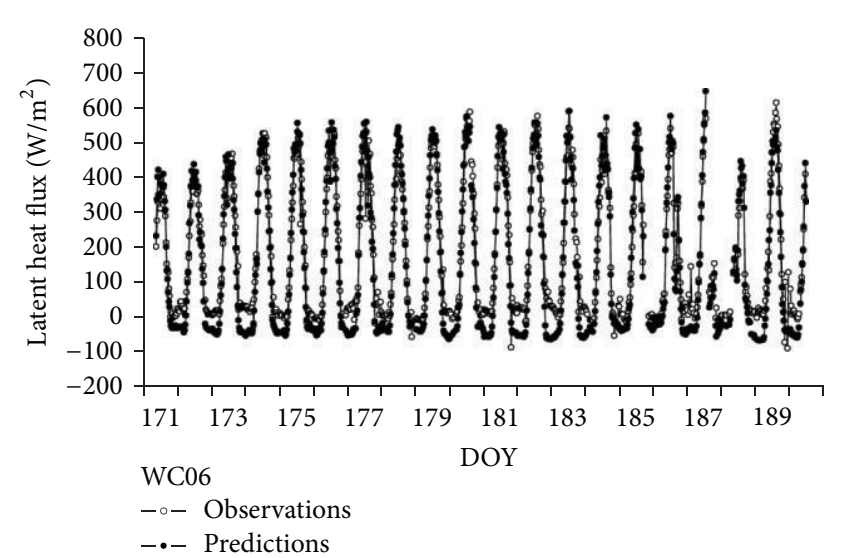

FIGURE 2: Comparison of observed (open circles) and predicted (solid dots) latent heat flux $\left(\mathrm{W} / \mathrm{m}^{2}\right)$ for WC06. DOY denotes the day number of the year in 2002 .

model performance for other sites are listed in Table 2. Overall, the comparison reveals that this model can effectively describe the daily evapotranspiration variations. Secondly, scatter plots of modeled results against observations were applied to the sites with the same land cover. Figure 4 shows the evapotranspiration predictions against observations from all corn sites. For the corn sites, 3824 samples are used. Most of the points are evenly distributed along the 1:1 line, indicating a good fitness of the modeled results to the observations. The $R^{2}$ (coefficient of determination) is 0.90; MAD and RMSD are $44.51 \mathrm{~W} / \mathrm{m}^{2}$ and $58.52 \mathrm{~W} / \mathrm{m}^{2}$. The slope and the intercept of the fitted line are 1.096 and $-35.8 \mathrm{~W} / \mathrm{m}^{2}$. For the soybean sites, 4494 samples are used. Figure 5 illustrates the evapotranspiration predictions against observations from all soybean sites. Most of the points are close to the $1: 1$ line. The slope and the intercept of the fitted line are 1.083 and $-20.7 \mathrm{~W} / \mathrm{m}^{2}$. The $R^{2}$ is 0.88 ; MAD and RMSD are $35.45 \mathrm{~W} / \mathrm{m}^{2}$ and $49.46 \mathrm{~W} / \mathrm{m}^{2}$, respectively. The quantitative measures for the two categories of sites show that this model is robust to estimate latent heat flux.

4.2. ET Estimation with Remotely Sensed Data. Land surface flux on July 1, 2002, was derived for the SMACEX02 regions

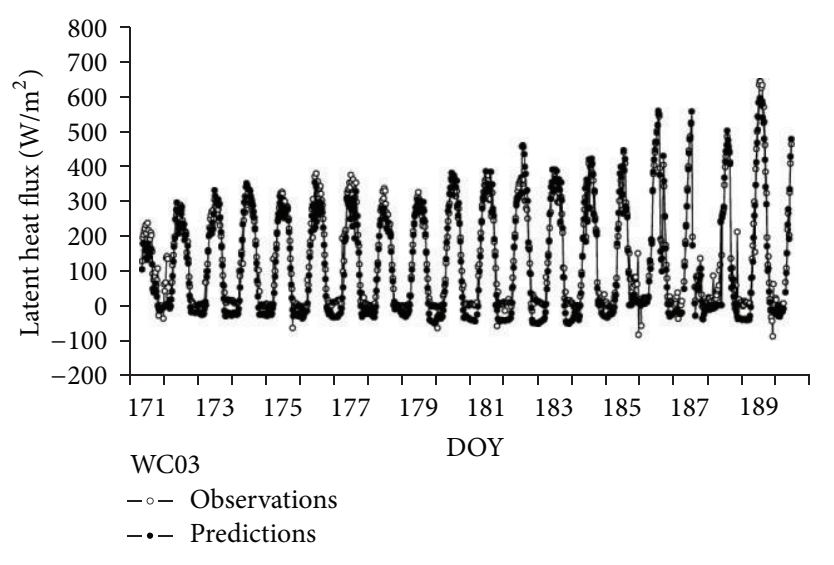

Figure 3: Comparison of observed (open circles) and predicted (solid dots) latent heat flux $\left(\mathrm{W} / \mathrm{m}^{2}\right)$ for $\mathrm{WC03}$. (The gap in the figure was due to lack of observations. DOY means the day number of the year in 2002.)

with remote sensing data and meteorological observations. The latent heat flux estimated from the Landsat based $(60 \mathrm{~m})$ variables is shown in Figure 6. The spatial patterns produced by the contrast between soybean and corn fields can be clearly seen in the Landsat based evapotranspiration maps. The difference between soybean and corn is about $80-120 \mathrm{~W} / \mathrm{m}^{2}$. A histogram was used to perform a further analysis of the retrieved result. Figure 7 presents the frequency of evapotranspiration across the study area with the Landsat based variables. The result indicates that bimodal histograms are found in the retrieval, which is in accordance with the soybean and corn fields. This may be associated with the LAI (leaf area index) values at different fields. The corn fields may have larger LAI values than the soybean fields, indicating larger transpiration rate in corn fields than the soybean fields. For the soybean and corn fields, two peaks of about $380 \mathrm{~W} / \mathrm{m}^{2}$ and $510 \mathrm{~W} / \mathrm{m}^{2}$ were found in the Figure 7. The mean latent heat flux and the standard deviation are $427.8 \mathrm{~W} / \mathrm{m}^{2}$ and $72.29 \mathrm{~W} / \mathrm{m}^{2}$, respectively, for the Landsat based estimates.

All the available tower observations were used to assess the estimated results. A comparison between the observed latent heat flux and the estimates derived from the Landsat 


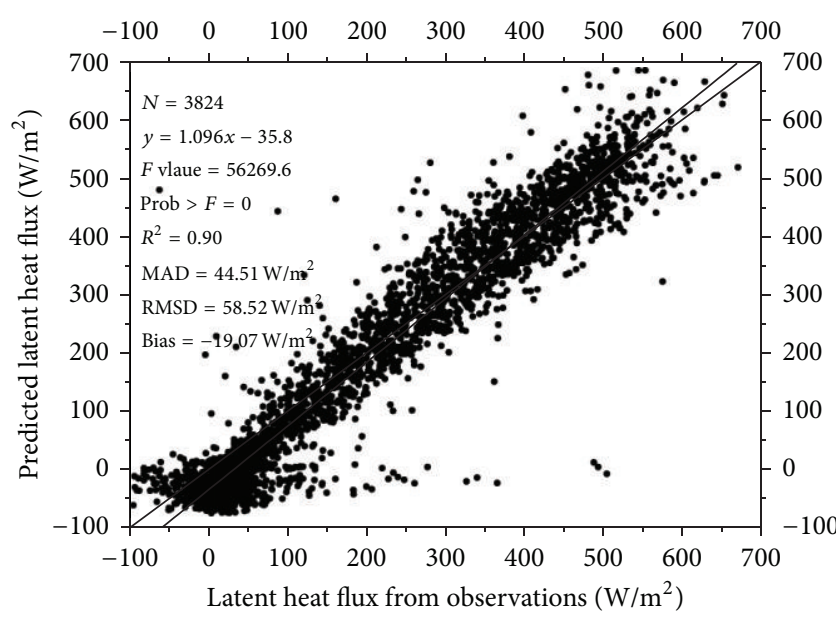

FIGURE 4: Model predicted latent heat flux $\left(\mathrm{W} / \mathrm{m}^{2}\right)$ versus eddy covariance based observations for all corn sites from DOY171-190, 2002.

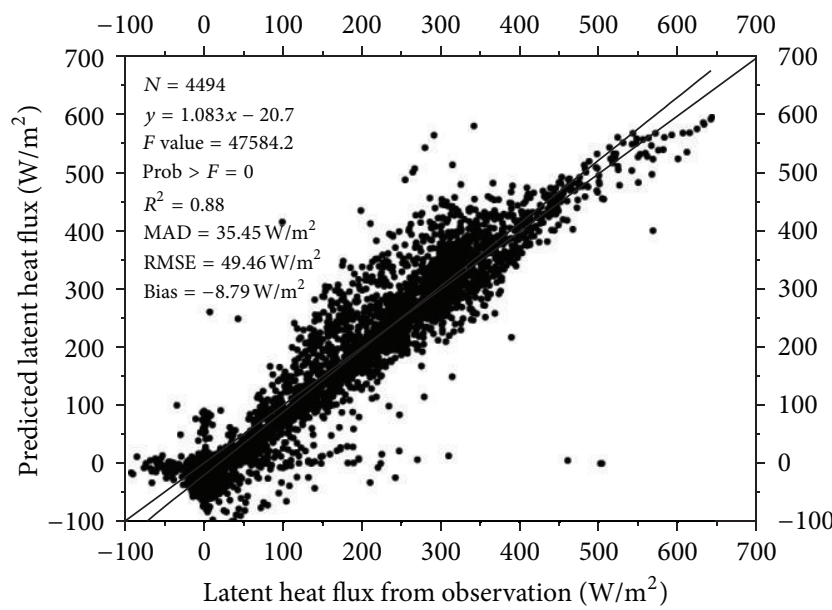

FIgURE 5: Model predicted latent heat flux $\left(\mathrm{W} / \mathrm{m}^{2}\right)$ versus eddy covariance based observations for all soybean sites from DOY171$190,2002$.

based variables is listed in Table 3. For most sites, except WC03 and WC161, the comparison indicates that the derived results are acceptable at Landsat based scales and the difference is lower than $70 \mathrm{~W} / \mathrm{m}^{2}$. However, a large deviation was found at WC03 and WC161. The discrepancies are $113.4 \mathrm{~W} / \mathrm{m}^{2}$ and $157.6 \mathrm{~W} / \mathrm{m}^{2}$. The WC03 is located at the junction of the different fields. The mixed pixel in the remote sensing data and the representation of the WC03 observations may be the explanation for the big disparity in the comparison. For WC161, Su et al. [72] also found a big difference in WC161 in their analysis. This can be attributed to the fact that the WC161 site is very close to the road and the corn field. Therefore, the observed results at WC161 represented the mixed underline covers, as the fetch of the eddy covariance system is about 100 meters [81]. Considering the representation of the observations and the mixed pixels in remote sensing imagery, the comparison indicates that the model is capable

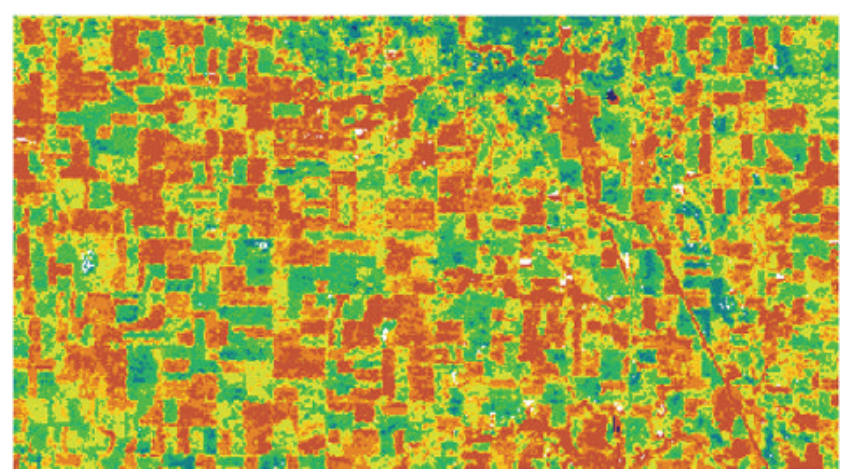

Latent heat flux $\left(\mathrm{W} / \mathrm{m}^{2}\right)$

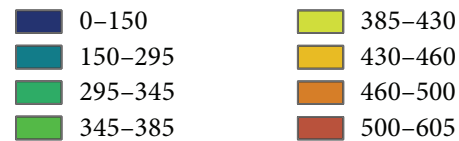

FIGURE 6: The latent heat flux $\left(\mathrm{W} / \mathrm{m}^{2}\right)$ estimated from Landsat based variables.

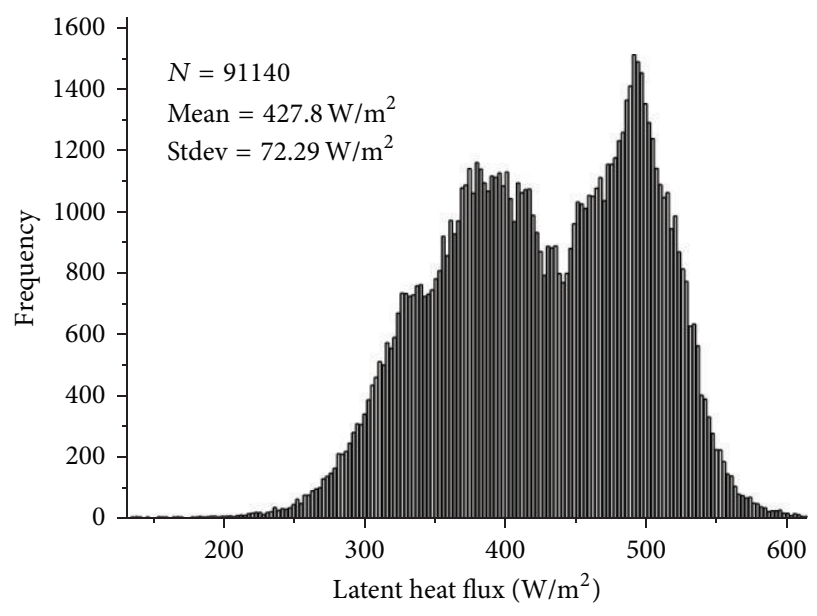

FIGURE 7: The histogram of the latent heat flux from different sensors based variables.

of computing reliable land surface heat flux over the study area.

In order to demonstrate the improvements of this model, the SEBS model was compared with the newly developed model. Figure 8 shows the comparison between estimates from SEBS model and the newly developed model. The modeled results from the newly developed model are larger than the estimates from the SEBS model. There are 91140 samples in the comparison; the MAD and RMSD are $37.21 \mathrm{~W} / \mathrm{m}^{2}$ and $43.08 \mathrm{~W} / \mathrm{m}^{2}$. The bias (SEBS model is the reference model) is $13.18 \mathrm{~W} / \mathrm{m}^{2}$. The disparity between these models may be attributed to three main reasons. Firstly, the forcing energy for $E T$ is quite different in these two models. In the SEBS model, which is based on the surface energy balance, the net radiation minus soil heat flux $\left(R_{n}-G\right)$ is assumed as the potential energy for ET. The advection effect is not considered in the SEBS model. However, in the 


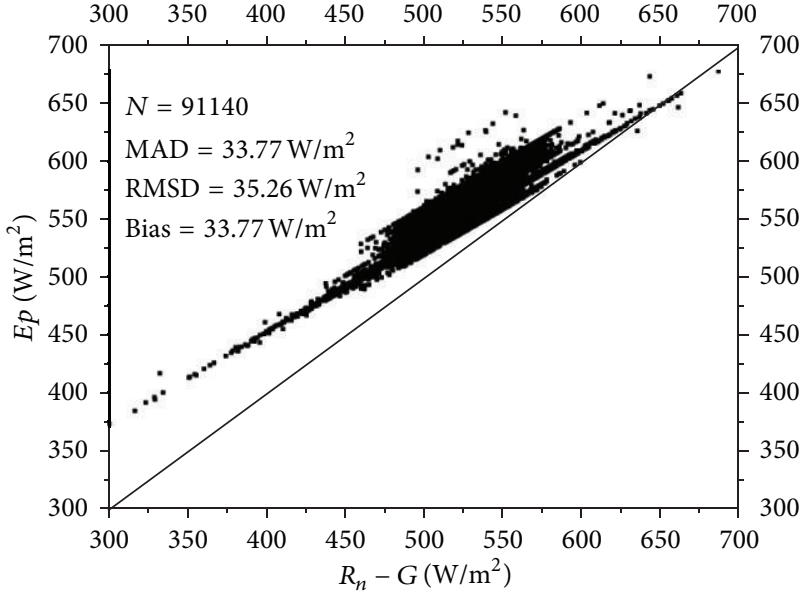

(a)

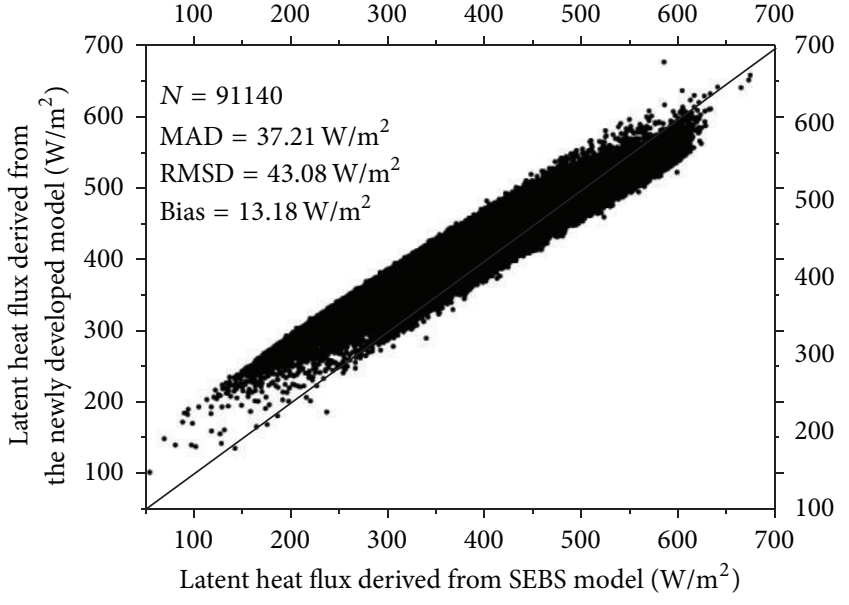

(b)

FIGURE 8: An intercomparison of the SEBS model and the newly developed model. (a) Comparison of the forcing energy $\left(\mathrm{W} / \mathrm{m}^{2}\right.$ ) used in SEBS and the newly developed model. (b) Comparison of the latent heat flux $\left(\mathrm{W} / \mathrm{m}^{2}\right)$ estimates from SEBS and the newly developed model.

TABLE 3: Comparison between the observed latent heat flux and the estimates derived from Landsat-based variables.

\begin{tabular}{lccc}
\hline $\begin{array}{l}\text { Site } \\
\text { name }\end{array}$ & $\begin{array}{c}\text { Tower } \\
\text { Observations } \\
\left(\mathrm{W} / \mathrm{m}^{2}\right)\end{array}$ & $\begin{array}{c}\text { Landsat-bsed } \\
\text { Estimates } \\
\left(\mathrm{W} / \mathrm{m}^{2}\right)\end{array}$ & Difference* \\
\hline WC03 & 354 & 467.4 & 113.4 \\
WC06 & 506 & 540.9 & 34.9 \\
WC13 & & 304.1 & \\
WC14 & & 414.8 & \\
WC151 & 488 & 524.1 & 36.1 \\
WC152 & 475 & 516.7 & 41.7 \\
WC161 & 299 & 456.6 & 157.6 \\
WC162 & & 445.9 & \\
WC23 & 392 & 329.3 & -62.7 \\
WC24 & 533 & 467.5 & -65.5 \\
WC25 & & 392.1 & \\
WC33 & 472 & 413.8 & -58.2 \\
\hline
\end{tabular}

${ }^{*}$ Difference referred as estimated value minus observed values.

newly developed model, advection is accounted for in the model development and the potential ET is determined as the potential energy for ET. Secondly, the parameterization of aerodynamic resistance is different in our model development. In the newly developed model, the empirical function for $Z_{o h}$ is applied in this study, while in SEBS model, a different parameterization for $Z_{o h}$ is developed. This may be another reason for the disparity of the comparison. Thirdly, the advection effect is not significant in the study area. Figure 8(a) presents the comparison between potential ET and $R_{n}-G$. Over the 91140 samples used in the comparison, the MAD and RMSD are $33.77 \mathrm{~W} / \mathrm{m}^{2}$ and $35.77 \mathrm{~W} / \mathrm{m}^{2}$, respectively. Potential ET is shown to be larger than $R_{n}-G$. The bias is $33.77 \mathrm{~W} / \mathrm{m}^{2}$.Therefore, the estimates from the two models are comparable. Although the difference does not seem to be large in this comparison, the approaches used to derive the ET estimation are quite different.

4.3. Daily ET Estimation. The evaporative fraction method is often applied to daily ET estimation. However, quite different conclusions were drawn by different researchers $[44,47]$. Developing an accurate extrapolate method from instantaneous estimates is imperative in regional ET estimation based on remotely sensed data. Equation (11) clearly demonstrates the relationship between surface resistance and CWSI. Therefore, surface resistance can be derived from CWSI. In this study, the surface resistance is assumed to be constant on a daily basis and daily ET can be retrieved based on the Penman-Monteith equation. Figure 9 shows the spatial distribution of surface resistance estimated from Landsat based variables. The surface resistance ranges from 0 to $420 \mathrm{~s} / \mathrm{m}$. The urban area shows the maximum value of surface resistance $(310-420 \mathrm{~s} / \mathrm{m})$, while the area along the river shows the lowest surface resistance $(0-20 \mathrm{~s} / \mathrm{m})$. The surface resistance of soybean fields is shown to be higher than that of the corn fields and the difference is about $50-80 \mathrm{~s} / \mathrm{m}$. As soon as the surface resistance is available, it becomes operational to estimate daily ET based on the PenmanMonteith equation. Figure 9 presents the spatial distribution of daily ET over the study area. The spatial pattern of daily ET is quite opposite to the surface resistance. The urban area shows the smallest values of daily ET $(0-3.3 \mathrm{~mm})$, while the area along the river shows a maximum of daily ET values (10.0-11.5 mm). Daily ET for the soybean fields is about 5.0$8.0 \mathrm{~mm}$, while daily ET for the corn fields is about $8-10.5 \mathrm{~mm}$.

To evaluate the performance of this new extrapolate method, daily ET ( $\mathrm{mm}$ ) derived from sites observations was used. Table 4 lists the tower observations, adjusted tower observations, estimates from the model, and discrepancy (the difference between estimates and adjusted observations) for every site of the study area. The estimates are comparable with the adjusted tower observations at sites WC06, WC24, WC25, 

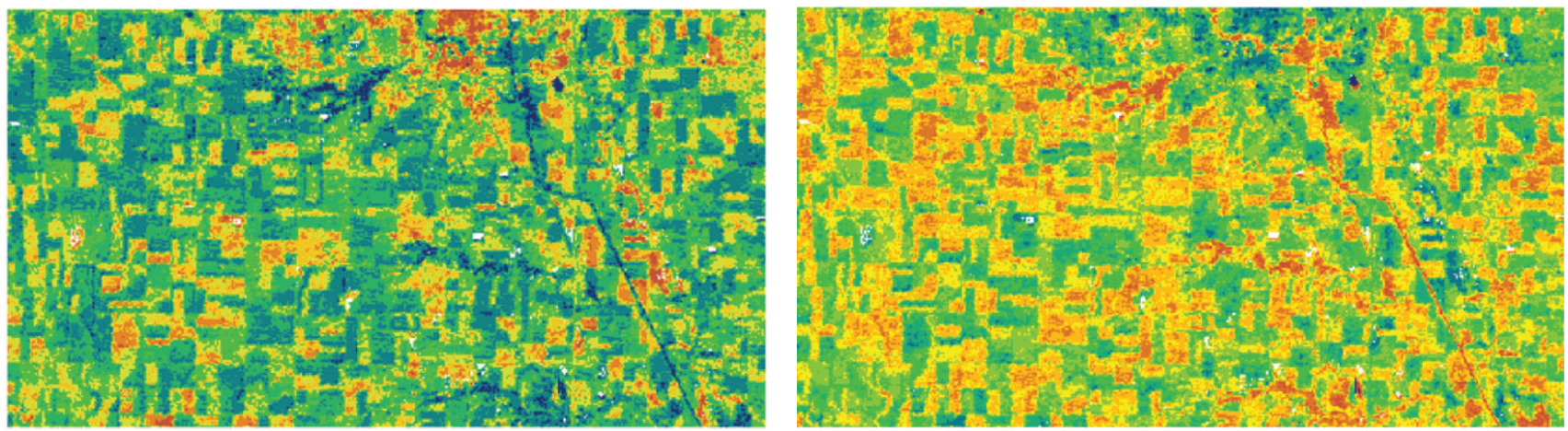

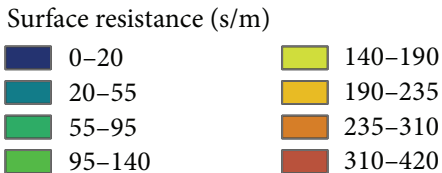

(a)

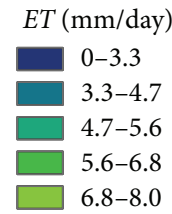

8.0-9.0

$9.0-10.0$

$10.0-11.0$

$11.0-11.5$

(b)

FiguRE 9: Surface resistance ( $\mathrm{s} / \mathrm{m})$ and daily ET ( $\mathrm{mm} /$ day) estimated from Landsat based variables over Walnut Creek catchment for July 1, 2002 .

TABLE 4: Comparison between the observed daily ET and the extrapolated daily ET from Landsat-based variables.

\begin{tabular}{lccc}
\hline $\begin{array}{l}\text { Tower } \\
\text { name }\end{array}$ & $\begin{array}{c}\text { Tower observations } \\
(\mathrm{mm})\end{array}$ & Estimates $(\mathrm{mm})$ & Difference $^{*}$ \\
\hline WC06 & 7.1 & 8.3 & 1.2 \\
WC24 & 7.1 & 7.8 & 0.7 \\
WC25 & 4.9 & 6.3 & 1.3 \\
WC33 & 6.6 & 6.4 & -0.2 \\
WC151 & 7.0 & 9.3 & 2.2 \\
WC152 & 6.2 & 9.6 & 3.4 \\
WC03 & 5.9 & 9.2 & 3.3 \\
WC13 & - & 5.3 & - \\
WC23 & 5.9 & 6.1 & 0.2 \\
WC14 & - & 7.5 & - \\
WC161 & 4.6 & 8.6 & 4.0 \\
WC162 & - & 8.2 & - \\
\hline
\end{tabular}

${ }^{*}$ Difference refers to estimated value minus observed values.

WC33, and WC23, while large differences were also found at WC151, WC152, WC03, and WC161. For site WC03, the land cover was classified as soybean in the field notes, but it was located in a corn field based on the provided coordinates [73]. Therefore, the large differences may be attributed to the parameterization of the vegetation height. For WC03 and WC161, the difference can be as large as $3.4 \mathrm{~mm}$ and $4.0 \mathrm{~mm}$. Large differences are found in the instantaneous comparison in Section 4.2 (Table 2). The mixed pixels in remote sensing imagery may contribute to large disparity. In addition, the observations from the eddy covariance system are seldom validated. Many problems related to $E C$ have not been fully solved. Firstly, many field observations of surface heat and vapor fluxes often fail to reach closure of the surface energy budget $[55,82,83]$. Secondly, the correction methods proposed by Twine et al. [74] are used frequently, but little is known about the accuracy of these correction methods. Advection is not accounted for in the forcing energy balance closure method and many field measurements indicate that $E T$ can often exceed net incoming radiation due to advection from the surrounding landscape $[42,43]$. Considering the above reasons, the comparison of the estimates and the observations from the towers listed in Table 3 may only provide a reference for the model's performance.

\section{Discussion}

The impact of advection on local energy balance and ET has long been reported by different researchers. In some extreme conditions, ET can even be greater than the net incoming radiation [37, 42, 43]. However, many remote sensing models still define $\left(R_{n}-G\right)$ as the only available energy used for $E T$ and this may cause errors under advective environments. In this study, a new model accounting for advection was proposed to estimate ET. This newly developed model is based on the CWSI concept and takes the advection effect into consideration. For the local scale evaluation, it is found that the model can effectively characterize the daily variations of evapotranspiration and the modeled results show good agreement with the site observations. For the regional scale, this model can characterize the spatial variations of land surface heat flux at the Landsat based scales.

Vegetation height is a very important parameter in the model development. In this study, the land surface classification from Landsat is applied to derive the vegetation height. This simplified method may cause some errors in the ET retrievals. This may be one of the reasons for the large 
disparity at WC03 and WC161 in Tables 3 and 4. The soil heat flux is an important component in the energy balance equation. However, the importance of the soil heat flux is not sufficiently considered. The parameterization proposed by Choudhury et al. [79] was applied in this study. This may be another reason for the large disparity at WC03 and WC06. Further research is needed for the parameterization of vegetation height and the soil heat flux.

Many problems are related to the precise observation of the actual evapotranspiration at the site scale. Eddy covariance approach provides a direct way for observing the actual evapotranspiration. However, there are two problems related to this approach. Firstly, it is well recognized that field measurements of surface heat fluxes often fail to reach closure of the surface energy budget [74, 83, 84]. The correction methods proposed by Twine [74] are used frequently, but little is known about the accuracy of these correction methods. Secondly, the location of the site and spatial representation of the observation are another problem related to this approach. The disparity of spatial scale in the eddy covariance approach and in the model estimates is a difficult problem associated with the validation results in Tables 3 and 4 . Therefore, eddy covariance approach needs more analysis before it can be used for validation of regional scale estimates. Although it has its limitations, observations from eddy covariance provide a good reference for the regional estimates based on remote sensing.

A reliable temporal extrapolation method is imperative for regional ET estimation based on remotely sensed data. The evaporative fraction and $K c$ method are a complicated combination of weather conditions, soil moisture, and biophysical conditions, as suggested by Crago [46]. In this study, the surface resistance was derived from CWSI, and then daily ET is estimated based on the Penman-Monteith equation.

The parameterization of aerodynamic resistance is very important in this newly developed model. In this study, the aerodynamic resistance was determined on the basis of the Monin-Obukhov surface layer similarity theory proposed by Brutsaert [63]. Liu et al. [62] evaluated eight parameterizations for aerodynamic resistance and pointed out that the roughness length for heat and vapor transfer is a crucial parameter. The empirical formula proposed by Kustas et al. [70] was used in this study. More research is needed to validate or observe aerodynamic resistance with high accuracy.

\section{Conclusions}

In this study, a new model was proposed to estimate ET. This model is based on the crop water stress index (CWSI) concept and clear relationship was found between CWSI and surface resistance. There are two attractive features of this model. Firstly, advection effects are accounted for in the model parameterization. Secondly, surface resistance can be derived from CWSI and can be used for extrapolating instantaneous estimates to daily values.

Both local scale evaluation with sites observations and regional scale evaluation with a remotely dataset from Landsat $7 \mathrm{ETM}+$ were carried out to assess the performance of this model. Local scale evaluation indicates that this newly developed model can effectively characterize the daily variations of evapotranspiration and the predicted results show good agreement with the site observations. Regional scale evaluation shows that the model can capture the spatial variations of the evapotranspiration at the Landsat based scale. Clear spatial patterns were observed at the Landsat based scale and are closely related to the dominant land covers, corn, and soybean. In addition, the surface resistance derived from instantaneous CWSI was applied to the Penman-Monteith equation to estimate daily ET. The evaluation indicates that the model is capable of estimating reliable surface heat fluxes. Several issues are unresolved, such as the energy balance closure problem related to observations from the eddy covariance system and the spatial heterogeneity in the mixed pixels. More research is needed to parameterize the aerodynamic resistance and to observe ET with a higher accuracy in order to minimize the uncertainties in the ET modeling and evaluation.

\section{Acknowledgments}

This work is supported jointly by the Project of National Natural Science Foundation of China (41171286), the National Basic Research Program of China (2010CB950904), and the International S\&T Cooperation Program of China (2013DFG21010). Thanks is given to the organizers and participants in SMEX02 and the National Snow and Ice Data Center (http://nsidc.org/) for providing the datasets used in this study.

\section{References}

[1] W. Brutsaert, Hydrology: An Introduction, Cambridge University Press, New York, NY, USA, 2005.

[2] C. Priestley and R. Taylor, "On the assessment of surface heat flux and evaporation using large-scale parameters," Monthly Weather Review, vol. 100, no. 2, pp. 81-92, 1972.

[3] R. A. Betts, P. M. Cox, M. Collins, P. P. Harris, C. Huntingford, and C. D. Jones, "The role of ecosystem-atmosphere interactions in simulated Amazonian precipitation decrease and forest dieback under global climate warming," Theoretical and Applied Climatology, vol. 78, no. 1-3, pp. 157-175, 2004.

[4] J. P. Goutorbe, T. Lebel, A. Tinga, P. Bessemoulin, and J. Brouwer, "A large-scale study of land-atmosphere interactions in the semi-arid tropics (HAPEX-Sahel)," in Exchange Processes at the Land Surface for a range of space and Time scales, H. J. Bolle, R. A. Feddes, and J. D. Kalma, Eds., vol. 212, pp. 357-364, AHS Press.

[5] D. M. Lawrence, P. E. Thornton, K. W. Oleson, and G. B. Bonan, "The partitioning of evapotranspiration into transpiration, soil evaporation, and canopy evaporation in a GCM: impacts on land-atmosphere interaction," Journal of Hydrometeorology, vol. 8, no. 4, pp. 862-880, 2007.

[6] W. Brutsaert and M. B. Parlange, "Hydrologic cycle explains the evaporation paradox," Nature, vol. 396, no. 6706, article 30, 1998.

[7] G. Fu, S. P. Charles, and J. Yu, "A critical overview of pan evaporation trends over the last 50 years," Climatic Change, vol. 97, no. 1, pp. 193-214, 2009. 
[8] M. L. Roderick and G. D. Farquhar, "The cause of decreased pan evaporation over the past 50 years," Science, vol. 298, no. 5597, pp. 1410-1411, 2002.

[9] R. G. Allen, L. S. Pereira, D. Raes, and M. Smith, "Crop evapotranspiration guidelines for computing crop water requirements," FAO Irrigation and Drainage Paper 56, FAO, Rome, 1998.

[10] S. Liang, Advances in Land Remote Sensing: System, Modelling, Inversion and Application, Springer, New York, NY, USA, 2008.

[11] R. Jackson, R. Reginato, and S. Idso, "Wheat canopy temperature: a practical tool for evaluating water requirements," Water Resources Research, vol. 13, no. 3, pp. 651-656, 1977.

[12] R. D. Jackson, M. S. Moran, L. W. Gay, and L. H. Raymond, "Evaluating evaporation from field crops using airborne radiometry and ground-based meteorological data," Irrigation Science, vol. 8, no. 2, pp. 81-90, 1987.

[13] M. Williams, A. D. Richardson, M. Reichstein et al., "Improving land surface models with FLUXNET data," Biogeosciences, vol. 6, no. 7, pp. 1341-1359, 2009.

[14] K. Zhang, J. S. Kimball, Q. Mu, L. A. Jones, S. J. Goetz, and S. W. Running, "Satellite based analysis of northern ET trends and associated changes in the regional water balance from 1983 to 2005," Journal of Hydrology, vol. 379, no. 1-2, pp. 92-110, 2009.

[15] M. Jung, M. Reichstein, P. Ciais et al., "Recent decline in the global land evapotranspiration trend due to limited moisture supply," Nature, vol. 467, no. 7318, pp. 951-954, 2010.

[16] M. C. Anderson, J. M. Norman, W. P. Kustas, R. Houborg, P. J. Starks, and N. Agam, "A thermal-based remote sensing technique for routine mapping of land-surface carbon, water and energy fluxes from field to regional scales," Remote Sensing of Environment, vol. 112, no. 12, pp. 4227-4241, 2008.

[17] M. C. Anderson, J. M. Norman, J. R. Mecikalski, J. A. Otkin, and W. P. Kustas, "A climatological study of evapotranspiration and moisture stress across the continental United States based on thermal remote sensing: 1. Model formulation," Journal of Geophysical Research D, vol. 112, no. 10, Article ID D10117, 2007.

[18] W. G. M. Bastiaanssen, M. Menenti, R. A. Feddes, and A. A. M. Holtslag, "A remote sensing surface energy balance algorithm for land (SEBAL): 1. Formulation," Journal of Hydrology, vol. 212-213, no. 1-4, pp. 198-212, 1998.

[19] J. M. Norman, W. P. Kustas, and K. S. Humes, "Source approach for estimating soil and vegetation energy fluxes in observations of directional radiometric surface temperature," Agricultural and Forest Meteorology, vol. 77, no. 3-4, pp. 263-293, 1995.

[20] Z. Su, "The Surface Energy Balance System (SEBS) for estimation of turbulent heat fluxes," Hydrology and Earth System Sciences, vol. 6, no. 1, pp. 85-99, 2002.

[21] M. C. Anderson, J. M. Norman, G. R. Diak, W. P. Kustas, and J. R. Mecikalski, "A two-source time-integrated model for estimating surface fluxes using thermal infrared remote sensing," Remote Sensing of Environment, vol. 60, no. 2, pp. 195216, 1997.

[22] M. S. Moran, T. R. Clarke, Y. Inoue, and A. Vidal, "Estimating crop water deficit using the relation between surface-air temperature and spectral vegetation index," Remote Sensing of Environment, vol. 49, no. 3, pp. 246-263, 1994.

[23] G. J. Roerink, Z. Su, and M. Menenti, "S-SEBI: a simple remote sensing algorithm to estimate the surface energy balance," Physics and Chemistry of the Earth B, vol. 25, no. 2, pp. 147-157, 2000.
[24] L. Jiang and S. Islam, "Estimation of surface evaporation map over southern Great Plains using remote sensing data," Water Resources Research, vol. 37, no. 2, pp. 329-340, 2001.

[25] R. Zhang, X. Sun, W. Wang, J. Xu, Z. Zhu, and J. Tian, "An operational two-layer remote sensing model to estimate surface flux in regional scale: physical background," Science in China D, vol. 48, no. 1, pp. 225-244, 2005.

[26] R. Zhang, J. Tian, H. Su, X. Sun, S. Chen, and J. Xia, “Two improvements of an operational two-layer model for terrestrial surface heat flux retrieval," Sensors, vol. 8, no. 10, pp. 6165-6187, 2008.

[27] K. Wang, Z. Li, and M. Cribb, "Estimation of evaporative fraction from a combination of day and night land surface temperatures and NDVI: a new method to determine the Priestley-Taylor parameter," Remote Sensing of Environment, vol. 102, no. 3-4, pp. 293-305, 2006.

[28] S. Stisen, I. Sandholt, A. Nørgaard, R. Fensholt, and K. H. Jensen, "Combining the triangle method with thermal inertia to estimate regional evapotranspiration: applied to MSG-SEVIRI data in the Senegal River basin," Remote Sensing of Environment, vol. 112, no. 3, pp. 1242-1255, 2008.

[29] Y. Shu, S. Stisen, K. H. Jensen, and I. Sandholt, "Estimation of regional evapotranspiration over the North China Plain using geostationary satellite data," International Journal of Applied Earth Observation and Geoinformation, vol. 13, no. 2, pp. 192206, 2011.

[30] T. Carlson, "An overview of the "triangle method" for estimating surface evapotranspiration and soil moisture from satellite imagery," Sensors, vol. 7, no. 8, pp. 1612-1629, 2007.

[31] G. Petropoulos, T. N. Carlson, M. J. Wooster, and S. Islam, "A review of Ts/VI remote sensing based methods for the retrieval of land surface energy fluxes and soil surface moisture," Progress in Physical Geography, vol. 33, no. 2, pp. 224-250, 2009.

[32] H. A. Cleugh, R. Leuning, Q. Mu, and S. W. Running, "Regional evaporation estimates from flux tower and MODIS satellite data," Remote Sensing of Environment, vol. 106, no. 3, pp. 285304, 2007.

[33] Q. Mu, F. A. Heinsch, M. Zhao, and S. W. Running, "Development of a global evapotranspiration algorithm based on MODIS and global meteorology data," Remote Sensing of Environment, vol. 111, no. 4, pp. 519-536, 2007.

[34] Q. Mu, M. Zhao, and S. W. Running, "Improvements to a MODIS global terrestrial evapotranspiration algorithm," Remote Sensing of Environment, vol. 115, no. 8, pp. 1781-1800, 2011.

[35] J. D. Kalma, T. R. McVicar, and M. F. McCabe, "Estimating land surface evaporation: a review of methods using remotely sensed surface temperature data," Surveys in Geophysics, vol. 29, no. 4-5, pp. 421-469, 2008.

[36] Z.-L. Li, R. Tang, Z. Wan et al., "A review of current methodologies for regional evapotranspiration estimation from remotely sensed data," Sensors, vol. 9, no. 5, pp. 3801-3853, 2009.

[37] R. Allen, "Initial report on closure error from Eddy-Covariance Systems used in the regional advection perturbations in an irrigated desert (RAPID) - impacts on evapotranspiration," Technical Report, 1999, http://www.kimberly.uidaho.edu/ rallen/ equip/rapidrpl.pdf.

[38] J. Wang, G. Y. Gao, Y. Hu, Z. Shen, Y. Mitsuta, and K. Sahasi, "An overview of the Heife experiment in the Peoples-Republic-ofChina," in Exchange Processes at the Land Surface for a Range of Space and Time Scales, H. J. Bolle, R. A. Feddes, and J. D. Kalma, Eds., vol. 212, pp. 397-403, IAHS Press. 
[39] J. A. Tolk, S. R. Evett, and T. A. Howell, "Advection influences on evapotranspiration of alfalfa in a semiarid climate," Agronomy Journal, vol. 98, no. 6, pp. 1646-1654, 2006.

[40] J. A. Tolk, T. A. Howell, and S. R. Evett, "Nighttime evapotranspiration from alfalfa and cotton in a semiarid climate," Agronomy Journal, vol. 98, no. 3, pp. 730-736, 2006.

[41] R. Allen, A. Irmak, R. Trezza, J. M. H. Hendrickx, W. Bastiaanssen, and J. Kjaersgaard, "Satellite-based ET estimation in agriculture using SEBAL and METRIC," Hydrological Processes, vol. 25 , no. 26, pp. 4011-4027, 2011.

[42] T. R. Oke, "Advectively-assisted evapotranspiration from irrigated urban vegetation," Boundary-Layer Meteorology, vol. 17, no. 2, pp. 167-173, 1979.

[43] D. A. Rijks, "Water use by irrigated cotton in Sudan .3. Bowen ratios and advective energy," Journal of Applied Ecology, vol. 8, no. 3, pp. 643-663, 1971.

[44] J. L. Chávez, C. M. U. Neale, J. H. Prueger, and W. P. Kustas, "Daily evapotranspiration estimates from extrapolating instantaneous airborne remote sensing et values," Irrigation Science, vol. 27, no. 1, pp. 67-81, 2008.

[45] H. O. Farah, W. G. M. Bastiaanssen, and R. A. Feddes, "Evaluation of the temporal variability of the evaporative fraction in a tropical watershed," International Journal of Applied Earth Observation and Geoinformation, vol. 5, no. 2, pp. 129-140, 2004.

[46] R. D. Crago, "Conservation and variability of the evaporative fraction during the daytime," Journal of Hydrology, vol. 180, no. 1-4, pp. 173-194, 1996.

[47] J. C. B. Hoedjes, A. Chehbouni, F. Jacob, J. Ezzahar, and G. Boulet, "Deriving daily evapotranspiration from remotely sensed instantaneous evaporative fraction over olive orchard in semi-arid Morocco," Journal of Hydrology, vol. 354, no. 1-4, pp. 53-64, 2008.

[48] R. G. Allen, M. Tasumi, and R. Trezza, "Satellite-based energy balance for mapping evapotranspiration with internalized calibration (METRIC) - model," Journal of Irrigation and Drainage Engineering, vol. 133, no. 4, pp. 380-394, 2007.

[49] J. L. Monteith, "Evaporation and environment," in The State and Movementof Water in Living Organisms, G. E. Fog, Ed., vol. 19, pp. 205-234, Cambridge University Press, Cambridge, UK, 1965.

[50] R. J. Granger and D. M. Gray, "Evaporation from natural nonsaturated surfaces," Journal of Hydrology, vol. 111, no. 1-4, pp. 21-29, 1989.

[51] W. Brutsaert and H. Stricker, "An advection-aridity approach to estimate actual regional evapotranspiration," Water Resources Research, vol. 15, no. 2, pp. 443-450, 1979.

[52] R. D. Jackson, S. B. Idso, R. J. Reginato, and P. J. Pinter Jr., "Canopy temperature as a crop water stress indicator," Water Resources Research, vol. 17, no. 4, pp. 1133-1138, 1981.

[53] R. D. Jackson, W. P. Kustas, and B. J. Choudhury, "A reexamination of the crop water stress index," Irrigation Science, vol. 9, no. 4, pp. 309-317, 1988.

[54] W. L. Ehrler, "Cotton leaf temperatures as related to soil-water depletion and meteorological factors," Agronomy Journal, vol. 65, no. 3, pp. 404-409, 1973.

[55] H. A. R. De Bruin, O. K. Hartogensis, R. G. Allen, and J. W. J. L. Kramer, "Regional advection perturbations in an irrigated desert (RAPID) experiment," Theoretical and Applied Climatology, vol. 80, no. 2-4, pp. 143-152, 2005.

[56] M. Menenti and B. Choudhury, "Parameterization of land surface evaporation by means of location dependent potential evaporation and surface temperature range," in Exchange Processes at the Land Surface for a Range of Space and Time Scales, H. J. Bolle, R. A. Feddes, and J. D. Kalma, Eds., vol. 212, pp. 561568, IAHS Press, 1993.

[57] H. Liu, Y. Zhang, S. Liu, H. Jiang, L. Sheng, and Q. L. Williams, "Eddy-Covariance measurements of surface energy budget and evaporation in a cool season over southern open water in Mississippi," Journal of Geophysical Research D, vol. 114, no. D4, 2009.

[58] H. Liu, P. D. Blanken, T. Weidinger, A. Nordbo, and T. Vesala, "Variability in cold front activities modulating coolseason evaporation from a southern inland water in the USA," Environmental Research Letters, vol. 6, no. 2, Article ID 024022, 2011.

[59] B. J. Choudhury, R. J. Reginato, and S. B. Idso, "An analysis of infrared temperature observations over wheat and calculation of latent heat flux," Agricultural and Forest Meteorology, vol. 37, no. 1, pp. 75-88, 1986.

[60] L. Mahrt and M. Ek, "The influence of atmospheric stability on potential evaporation," Journal of Climate \& Applied Meteorology, vol. 23, no. 2, pp. 222-234, 1984.

[61] K. Yang, T. Koike, and D. Yang, "Surface flux parameterization in the Tibetan Plateau," Boundary-Layer Meteorology, vol. 106, no. 2, pp. 245-262, 2003.

[62] S. Liu, L. Lu, D. Mao, and L. Jia, "Evaluating parameterizations of aerodynamic resistance to heat transfer using field measurements," Hydrology and Earth System Sciences, vol. 11, no. 2, pp. 769-783, 2007.

[63] W. Brutsaert, Evaporation into the Atmosphere: Theory, History, and Applications, Springer, New York, NY, USA, 1982.

[64] C. A. Paulson, "Mathematical representation of wind speed nd temperature profiles in the unstable atmospheric surface layer," Journal of Applied Meteorology, vol. 9, no. 6, pp. 857-861, 1970.

[65] J. A. Businger, J. C. Wyngaard, Y. Izumi, and E. F. Bradley, "Fluxprofile relationships in the atmospheric surface layer," Journal of the Atmospheric Sciences, vol. 28, no. 2, pp. 181-189, 1971.

[66] E. K. Webb, G. I. Pearman, and R. Leuning, "Correction of flux measurements for density effects due to heat and water vapour transfer," Quarterly Journal Royal Meteorological Society, vol. 106, no. 447, pp. 85-100, 1980.

[67] G. G. Katul and M. B. Parlange, "A Penman-Brutsaert model for wet surface evaporation," Water Resources Research, vol. 28, no. 1, pp. 121-126, 1992.

[68] S. Liu, J. Bai, Z. Jia, L. Jia, H. Zhou, and L. Lu, "Estimation of evapotranspiration in the Mu Us Sandland of China," Hydrology and Earth System Sciences, vol. 14, no. 3, pp. 573-584, 2010.

[69] J. L. Monteith, Principles of Environmental Physics, Edward Arnold, London, UK, 1973.

[70] W. P. Kustas, B. J. Choudhury, M. S. Moran et al., "Determination of sensible heat flux over sparse canopy using thermal infrared data," Agricultural and Forest Meteorology, vol. 44, no. 3-4, pp. 197-216, 1989.

[71] W. P. Kustas, J. L. Hatfield, and J. H. Prueger, "The soil moistureatmosphere coupling experiment (SMACEX): background, hydrometeorological conditions, and preliminary findings," Journal of Hydrometeorology, vol. 6, no. 6, pp. 791-804, 2005.

[72] H. Su, M. F. McCabe, E. F. Wood, Z. Su, and J. H. Prueger, "Modeling evapotranspiration during SMACEX: comparing two approaches for local- and regional-scale prediction," Journal of Hydrometeorology, vol. 6, no. 6, pp. 910-922, 2005. 
[73] M. F. McCabe and E. F. Wood, "Scale influences on the remote estimation of evapotranspiration using multiple satellite sensors," Remote Sensing of Environment, vol. 105, no. 4, pp. 271285, 2006.

[74] T. E. Twine, W. P. Kustas, J. M. Norman et al., "Correcting EddyCovariance flux underestimates over a grassland," Agricultural and Forest Meteorology, vol. 103, no. 3, pp. 279-300, 2000.

[75] J. A. Sobrino, N. Raissouni, and Z.-L. Li, "A comparative study of land surface emissivity retrieval from NOAA data," Remote Sensing of Environment, vol. 75, no. 2, pp. 256-266, 2001.

[76] F. Li, T. J. Jackson, W. P. Kustas et al., "Deriving land surface temperature from Landsat 5 and 7 during SMEX02/SMACEX," Remote Sensing of Environment, vol. 92, no. 4, pp. 521-534, 2004.

[77] S. Liang, "Narrowband to broadband conversions of land surface albedo I algorithms," Remote Sensing of Environment, vol. 76, no. 2, pp. 213-238, 2001.

[78] S. Liang, C. J. Shuey, A. L. Russ et al., "Narrowband to broadband conversions of land surface albedo: II. Validation," Remote Sensing of Environment, vol. 84, no. 1, pp. 25-41, 2003.

[79] B. J. Choudhury, S. B. Idso, and R. J. Reginato, "Analysis of an empirical model for soil heat flux under a growing wheat crop for estimating evaporation by an infrared-temperature based energy balance equation," Agricultural and Forest Meteorology, vol. 39, no. 4, pp. 283-297, 1987.

[80] F. Baret, J. G. Clevers, and M. D. Steven, "The robustness of canopy gap fraction estimates from red and near-infrared reflectances: a comparison of approaches," Remote Sensing of Environment, vol. 54, no. 2, pp. 141-151, 1995.

[81] J. L. Chávez, C. M. U. Neale, L. E. Hipps, J. H. Prueger, and W. P. Kustas, "Comparing aircraft-based remotely sensed energy balance fluxes with Eddy-Covariance tower data using heat flux source area functions," Journal of Hydrometeorology, vol. 6, no. 6, pp. 923-940, 2005.

[82] J. L. Chávez, T. A. Howell, and K. S. Copeland, "Evaluating Eddy-Covariance cotton ET measurements in an advective environment with large weighing lysimeters," Irrigation Science, vol. 28, no. 1, pp. 35-50, 2009.

[83] T. Foken, "The energy balance closure problem: an overview," Ecological Applications, vol. 18, no. 6, pp. 1351-1367, 2008.

[84] T. Foken, F. Wimmer, M. Mauder, C. Thomas, and C. Liebethal, "Some aspects of the energy balance closure problem," Atmospheric Chemistry and Physics, vol. 6, no. 12, pp. 4395-4402, 2006. 

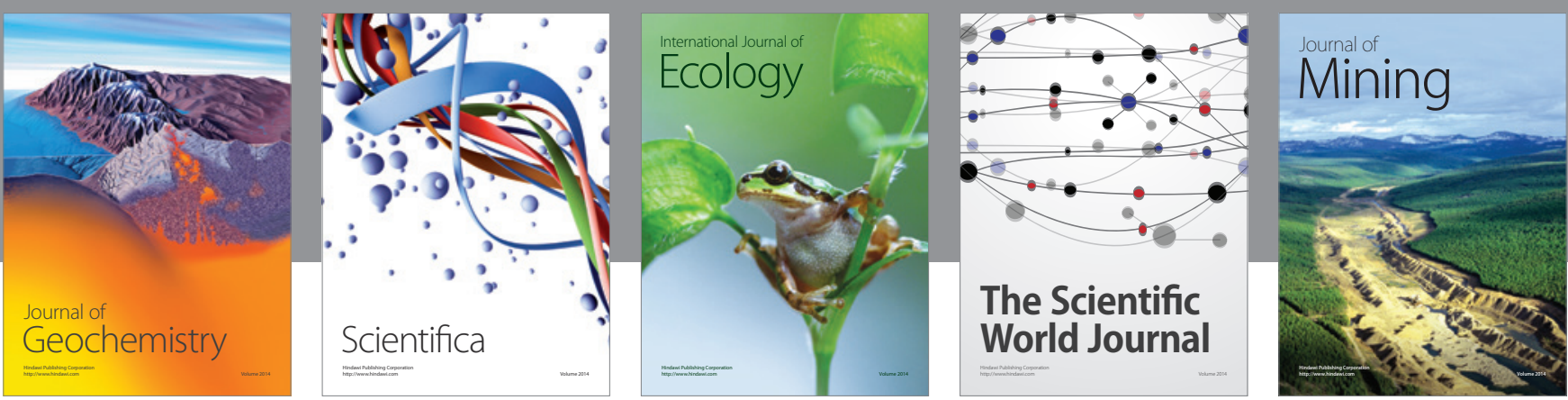

The Scientific World Journal
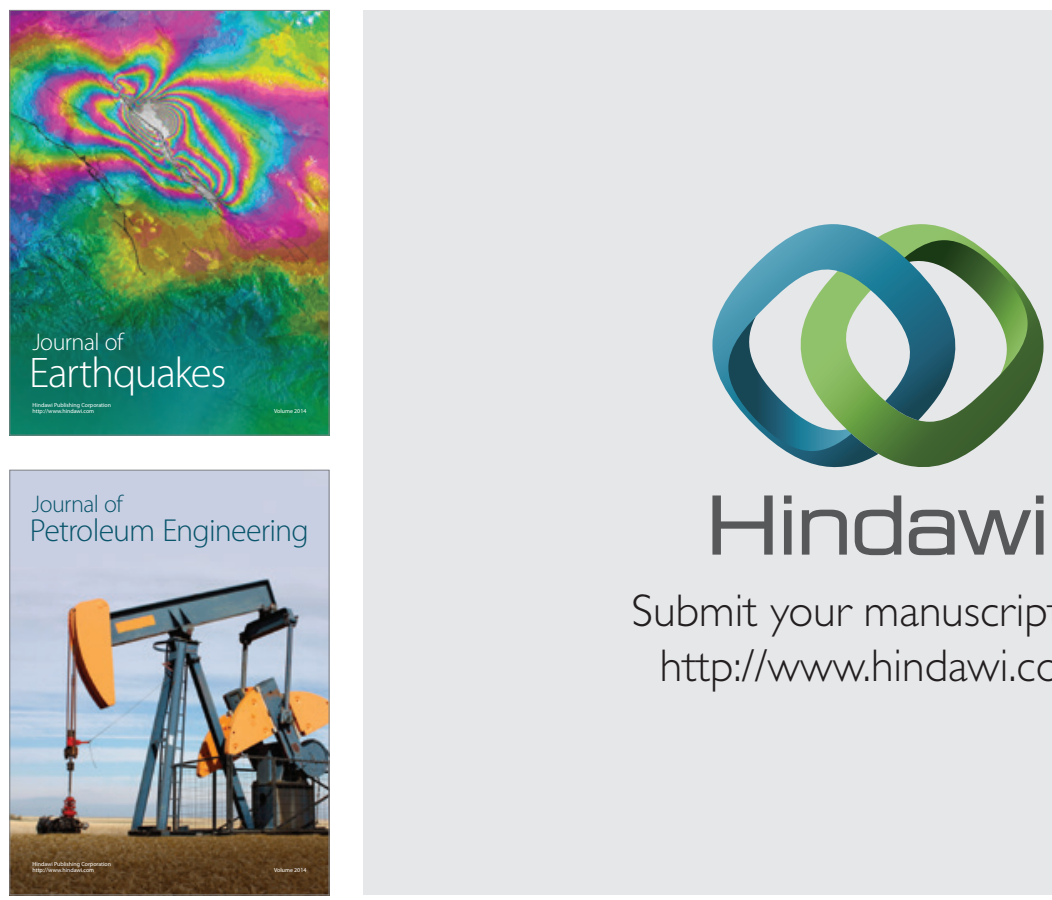

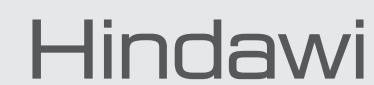

Submit your manuscripts at

http://www.hindawi.com
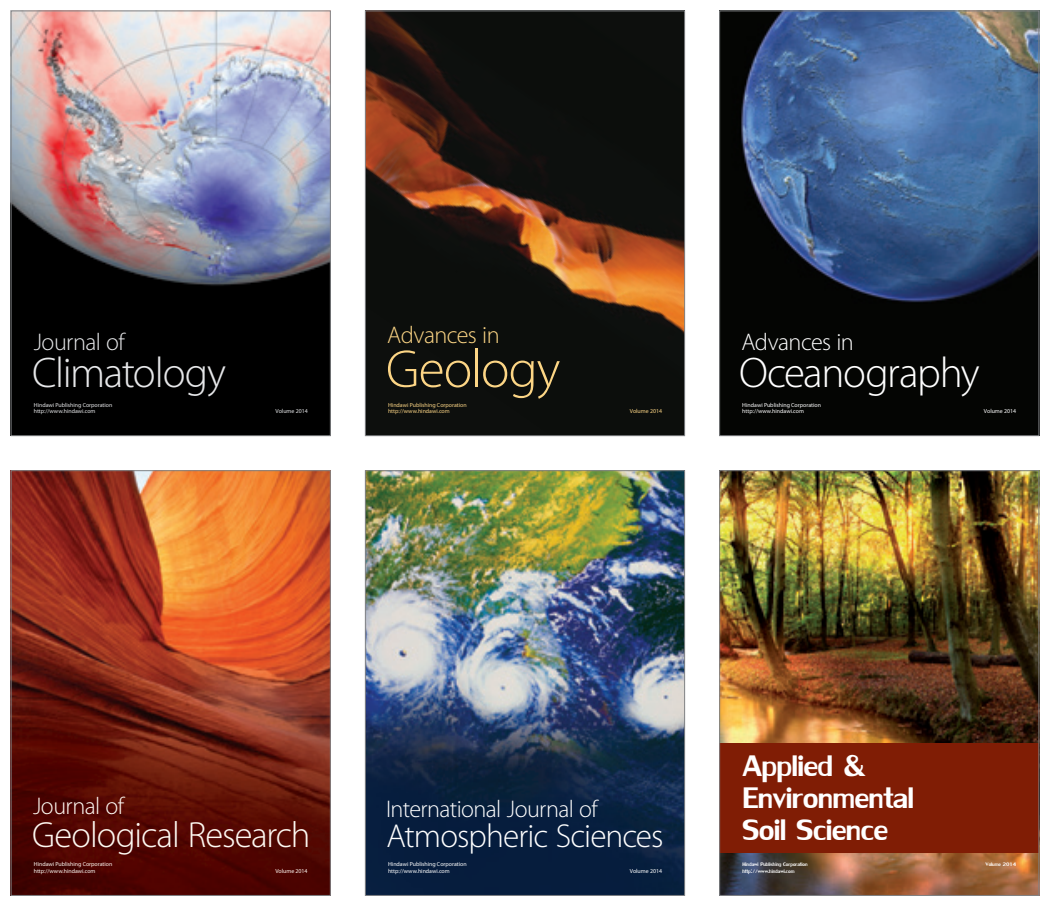
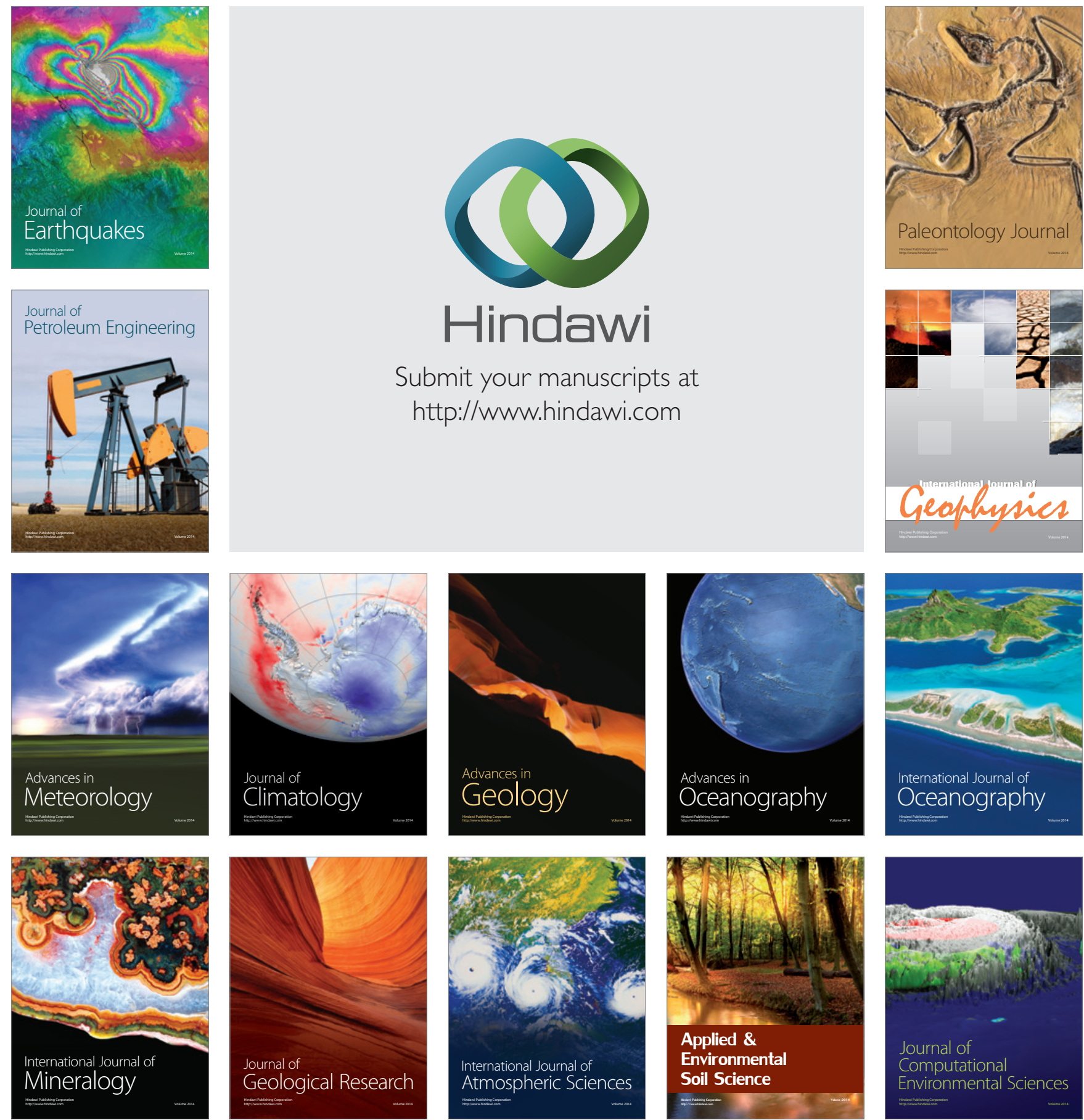